\title{
Exergy: Game Changer or Game Maker
}

Birol Kilkis

TTMD, Ankara Turkey

\begin{abstract}
Many standard practices of today in the High Performance and Sustainably Green Buildings simply rely on the First-Law of Thermodynamics and economic feasibility in their evaluation and ratings. Although these practices seem to be quite 'efficient' and green, new metrics, which are based on the Second-Law, namely exergy rationality metrics show that these practices are not feasible and environmentally advantageous, unless they are redesigned accordingly. For example, a simple ORC system using low-enthalpy geothermal source is not feasible, which means that such a system may save money and apparently energy but definitely destroys exergy compared to direct use of the thermal power from the geothermal well. This poster emphasizes the urgency of switching to exergy-based designs and practices.
\end{abstract}

\section{Introduction}

Figure 1 shows that from an exergy point of vies, it must be carefully watched whether it is more rational to use the thermal energy directly or convert it to electricity with low efficiency or both. In many cases-depending on the geothermal source temperature- it is more exergy-rational to keep the heat for thermal consumption.

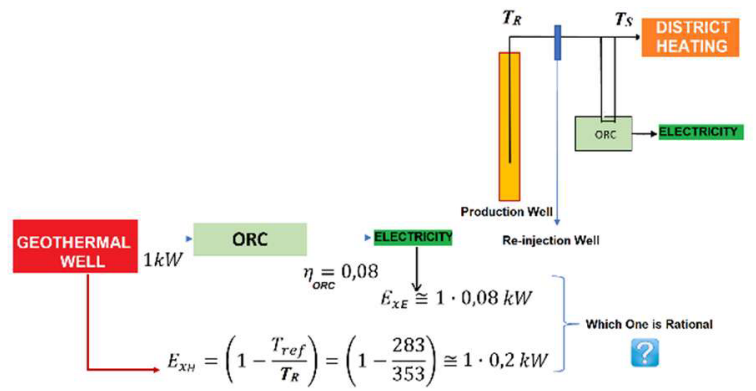

Figure 1. Exergy Rationale in Geothermal Energy.

\section{Model}

In order to give a complete insight into this subject matter, the following equations were derived for the specific purpose of the analysis.

$$
\begin{array}{r}
E_{X T}=E_{X E}+E_{X H}-E_{X P}-E_{X F} \\
C O P E X=\frac{E_{X T}}{\left(E_{X P}+E_{X F}\right)}
\end{array}
$$

The total exergy of the system is the exergy sum of electrical output and the thermal output minus the sum of exergy demand related to the electrical power demand of circulation pumps and the dry-cooling fan.Figure 1 shows the general arrangement of a geothermal energy driven ORC. Here the power output is split between power supply to the building and power supply to a ground-source heat pump, $X$ providing comfort heat (or cold). COPEX is the exergy-based coefficient of performance.

The following exergy-based equations, which are necessary to optimize the split ratio, $X$ describe the system performance. Here, if $X$ is equal to zero, then this is all electric case, if $X$ is equal to one, then this is all heat case.

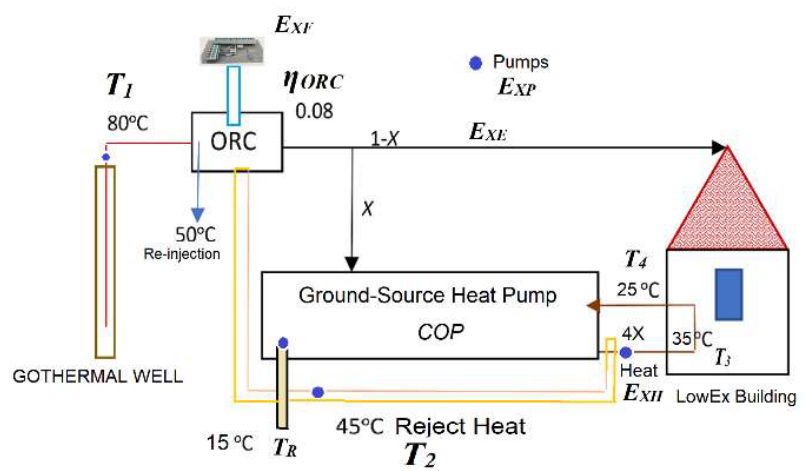

Figure 1. Geothermal Energy Driven ORC and Heat Pump.

$$
\begin{gathered}
E_{X E}=\eta_{O R C}(1-X) \\
\eta_{O R C}=a+b T_{1} \\
E_{X H}=X C O P\left(1-\frac{T_{3}}{T_{4}}\right) \\
C O P=g+h\left(T_{R}-T_{3}\right) \\
E_{X P}=c+d X^{2} \\
E_{X F}=\left(e \eta_{O R C}{ }^{-f}\right)
\end{gathered}
$$

If the objective is to optimize the split ratio, $X$, in terms of the above linearized equations -except for EXP- then Equation 1 needs to be differentiated with respect to $X$ and then equated to zero. The optimum solution is given by the following simple equation: 


$$
X_{\text {opt }}=\frac{C O P-\eta_{\text {orc }}}{2 d} \quad\{0 \leq X \leq 1\}
$$

\section{Application}

For example, if COP, $\eta$ ORC, and $d$ are $4,0.1$, and 3 respectively, then the optimum $X$ value will be 0.65 .

Coincidentally, if the First-Law would be used, then the same optimization equation would be obtained after differentiation. However, although the First-Law in this case seems useful and provides the same optimum $X$ value with the Second-Law and the energy amount is positive but the exergy amount is negative. Here comes the importance of the Second Law and the graphical solution in Figure 2 shows that the optimization has two separate regions and the system must be duly optimized after determining the break-even temperature. If the geothermal source temperature is higher than $T_{e}$, then ORC system is preferable if waste heat is utilized. Otherwise, the system must be an all heat system $(X=1)$. The break-even temperature $T_{e}$ is solved from Equations 2 and 3.

$$
T_{e}=\frac{\operatorname{COP}\left(1-\frac{T_{3}}{T_{4}}\right)-a}{b}
$$

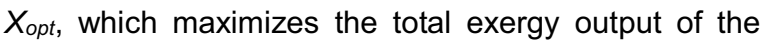
geothermal system with ORC shows that COP, $\eta_{O R C}$ and coefficient $d$ of the power demand of pumps and fans are the major factors. Often the pump and fan exergy demand are ignored but sometimes included in energy analysis. In fact, this model shows that due to large unit exergy difference between power and heat parasitic exergy losses are very important. That is why

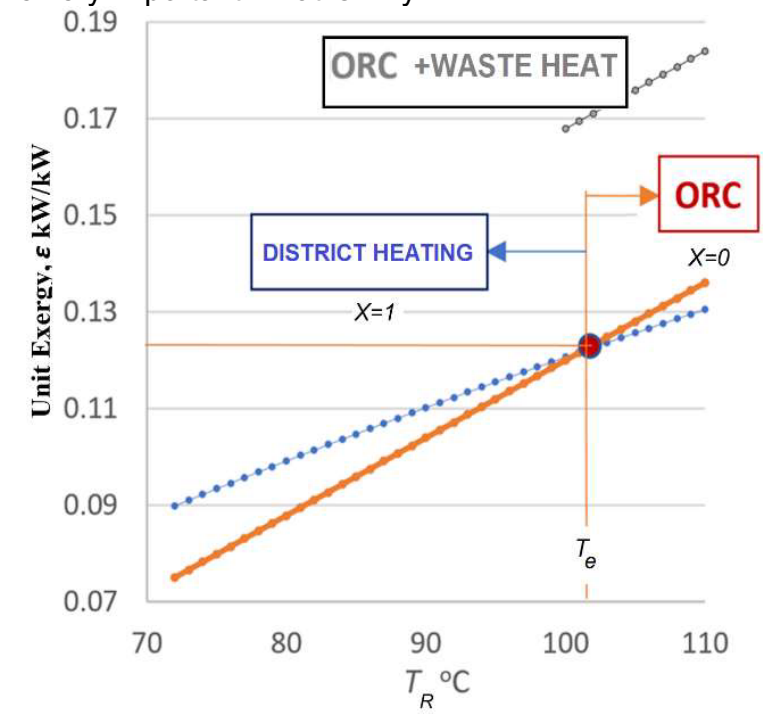

Figure 2. Break-Even Temperature for Heating or Power (Equation 10).

COPEX is less than one for the entire system when all parasitic losses are taken account with the Second-Law of Thermodynamics. According to Equation $10 T_{e}$ gets more relaxed with an increase in $a$ and $b$, which improve the ORC efficiency thus ORC becomes more favorable. If, however, COP increases then $T_{e}$ increases in favor of heat only case.

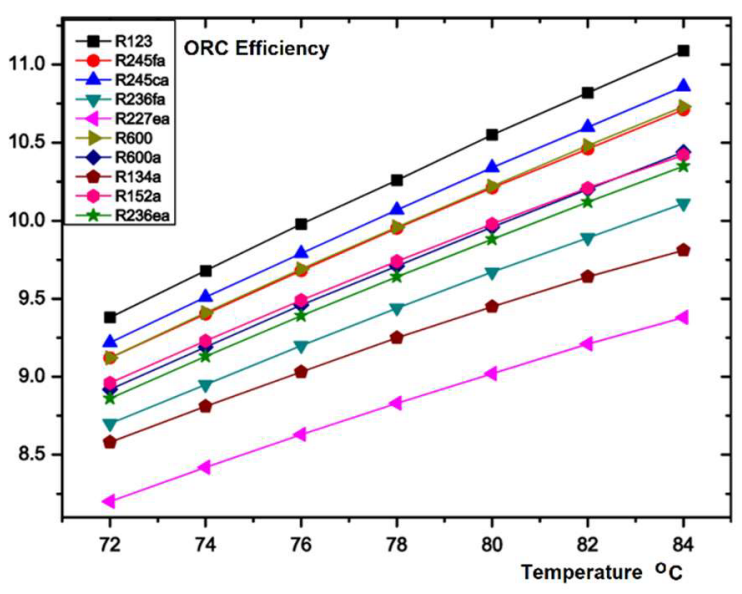

Figure 3. Linear Change of ORC Efficiency with Source Temperature (Equation 4).

Here it must be noted that both the ORC unit and the heat pump emit ozone depleting chemicals (ODC) and this must be kept in mind in questioning how ORC systems are environment friendly when coupled with geothermal energy and heat pumps. Geothermal energy sources also emit chemicals and $\mathrm{H}_{2} \mathrm{~S}$ gas long with $\mathrm{CO}_{2}$. Unless these non-condensable gases are completely retrieved, the environmental benefits deed to be seriously questioned.

\section{Game Changers}

It is often a practical application that two thermal energy sources with different temperatures (Exergy) are mixed for a common purpose. Figures 4 and 5 show that exergy is destroyed when two sources have quite different temperatures but it may be negligible otherwise.

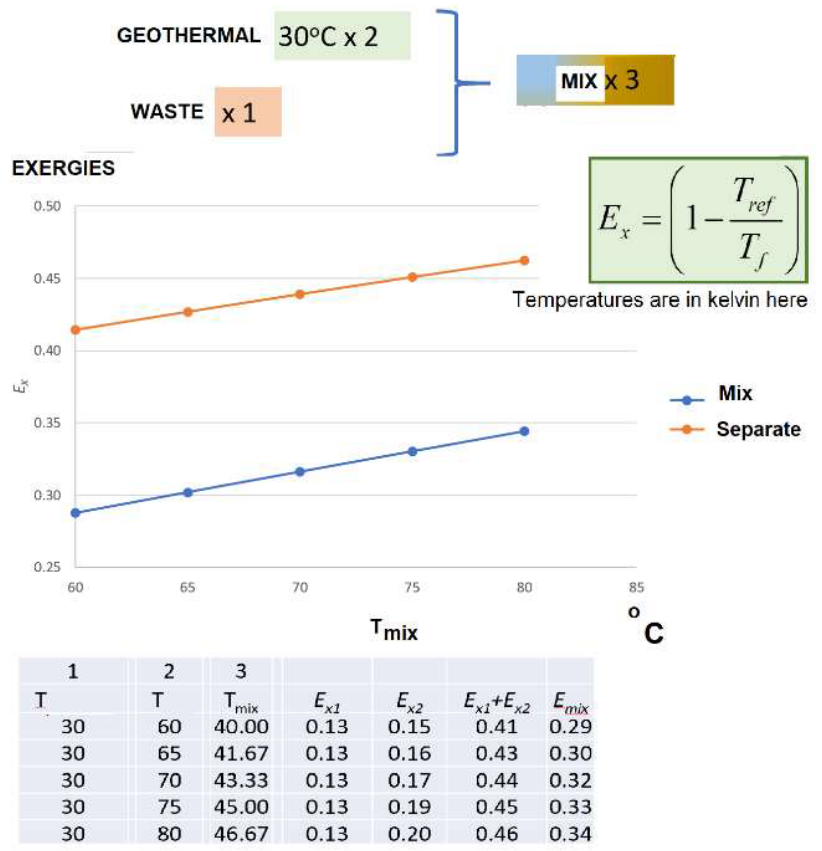

Figure 4. Disadvantage of Mixing two Thermal Sources with Different Exergy. 


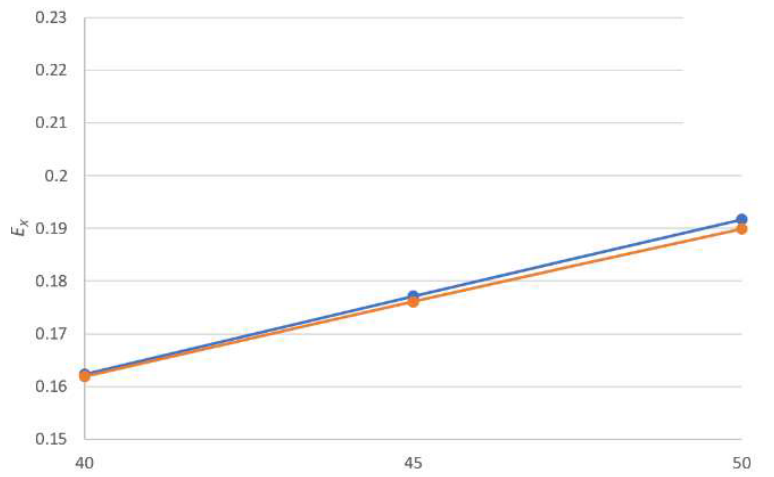

Figure 5. Mixing two Thermal Sources with Similar Exergy.

\section{Conclusions}

In order to electrify the HVAC sector by heat pumps especially in the EU countries the use of ORC technology is a relatively new trend where low-enthalpy geothermal energy resources and waste heat prevail. This is a viable approach within the scope of the First-Law of Thermodynamics but this condition usually does not hold true if a careful and optimum allocation of low-enthalpy energy sources and balancing with demand with different quality (exergy) and quantity (energy) is not characterized by the Second-Law of Thermodynamics along with the First-Law. Otherwise such applications in the built environment may increase $\mathrm{CO}_{2}$ emissions and ozone depleting potential (ODP) [1]. Carbon dioxide has been widely investigated for use as a working fluid in refrigeration cycles, because it has no ozone- depleting potential (ODP) and low global warming potential (GWP). It is also inexpensive, non-explosive, non-flammable and abundant in nature [2]. These innovations must accompany a dynamic control algorithm based on exergy approach presented in this poster. ORC systems seem to be a good company for low-enthalpy geothermal energy sources but they need a complete analysis and planning $[3,4]$. Such an approach will also be instrumental for other waste heat and cogeneration applications in the HVAC sector and the industry [5]. In conclusion, ORC is not a stand-alone option but only a component of al larger combination of several renewable components, systems and equipment [6].

\section{References}

[1] Kilkis, B. 2017. TTMD, Sustainability and Decarbonization Efforts of the EU: Potential Benefits of Joining Energy Quality (Exergy) and Energy Quantity (Energy) in EU Directives, A State-of- the Art Survey and Recommendations, Exclusive EU Position Report @2017 Birol Kilkis, TTMD 2017-1, Ankara, Turkey.

[2] Ismail, B. I. 2013. ORC-Based Geothermal Power Generation and $\mathrm{CO}_{2}$ - Based EGS for Combined Green Power Generation and $\mathrm{CO}_{2}$ Sequestration, Intech Open Access.

[3 Kilkis B. and Kilkis, San, 2014. Energy and Exergy Based Comparison of Utilizing Waste Heat of a

Cogeneration System for Comfort Cooling Using ORC Driven Chillers or Heat Pumps Versus
Absorption/Adsorption Cycles, ASME ORC 2013, Conference Proceedings, 7-8 October, De Doelen, Rotterdam, the Netherlands.

[4] Kilkis, B., Kilkis, Siir, and Kilkis, San. 2017. Optimum Hybridization of Wind Turbines, Heat Pumps, and Thermal Energy Storage Systems for Near Zero-Exergy Buildings (NZEXB) Using Rational Exergy Management Model, Paper No. 2, 12th IEA Heat Pump Conference, 15-18 May, Rotterdam 2017.

Papers on line,

$<$ https://www.eiseverywhere.com/ehome/index.php?event id $=165152 \&$ tabid $=558494>$

Last Visited on Feb/02/2019.

Also abstracted in print, pp: 179-180. Proceedings of 12th IEA Heat Pump Conference - ISBN 978- 90-9030412-0Rotterdam, June 2017.

[5] Kilkis, B., Kilkis, Ş. 2007. Exergy Optimization of Generated Electric Power Split in a Heat Pump Coupled Poly-Generation System, Poster Presentation, First European Conference on Polygeneration Technologies and Applications, October 16-17, Tarragona, Spain, 2007. [6] Kılkış B. and Kılkış, Şiir. 2018. Rational Exergy Management Model for Effective Utilization of LowEnthalpy Geothermal Energy Resources, Hittite Journal of Sciences and Engineering, 5, pp:59-73.

\section{Nomenclature}

a-h Various factors and powers of equations

$C O P$ Coefficient of Performance

COPEX Exergy-Based Coefficient of Performance

$E_{x} \quad$ Exergy, $\mathrm{kW}$ or $\mathrm{kW}-\mathrm{h}$

ODP Ozone Depleting Potential

ORC Organic Rankine Cycle

$T \quad$ Temperature, $\mathrm{K}$

$X \quad$ Power Split

Greek Symbols

$\varepsilon \quad$ Unit exergy, $\mathrm{kW} / \mathrm{kW}$

$\eta \quad$ First-Law Efficiency

\section{Subscripts}

\begin{tabular}{ll}
\hline$e$ & Break-even \\
$E$ & Electric \\
$F$ & Fan \\
$f$ & Source \\
$H$ & Thermal (Heat) \\
mix & Thermal mix \\
opt & Optimum \\
$R$ & Reservoir \\
$r e f$ & Reference \\
$P$ & Pump \\
$T$ & Total \\
$X, E X$ & Exergy
\end{tabular}

\section{Abbreviations}

EU European Union

HVAC Heating Ventilating and Air Conditioning

ODP Ozone Depleting Potential

ORC Organic Rankine Cycle 